\title{
Sistem Pakar Diagnosis Hama dan Penyakit Tanaman Hortikultura dengan Teknik Inferensi Forward dan Backward Chaining
}

\author{
Ginanjar Wiro Sasmito \\ Program Studi D4 Teknik Informatika, Politeknik Harapan Bersama \\ Jl. Mataram No. 09, Pesurungan Lor, Kota Tegal, Indonesia
}

\begin{abstract}
One of the obstacles to doing cultivation of horticulture plant is to overcome pest and disease. Pest and disease attack can decrease productivity and even causes harvest fail that influence toward one of income sources the country. Therefore the diagnose on pest and disease must be done fastly and accurately. One of horticulture plant is red onion and chili plant. An expert system is offered as the second choice after expert on consultation. Using Expert System Development Life Cycle (ESDLC) method, combination inference engine of and backward chaining for diagnosing pest and horticulture plant disease created as giving the solution. The technique of reasoning used in this research is the rule-based. The result of the research is an application that can be used to diagnosis pest and disease horticulture plant, that are red onion and chili. By this application, the farmer can determine quick action should be taken if the farm pests and diseases, without waiting for a consultation with an expert to do the handling. The application result also could be a learning system to the farmer about pest and disease horticulture plant.
\end{abstract}

Keywords : expert system;forward chaining;backward chaining;rule-based reasoning; ESDLC; horticulture plant.

Abstrak - Salah satu kendala melakukan budidaya tanaman hortikultura adalah dalam mengatasi hama dan penyakit. Serangan hama dan penyakit dapat menurunkan produktivitas dan bahkan menyebabkan gagal panen yang berpengaruh terhadap salah satu sumber devisa negara. Oleh karena itu, diagnosis terhadap hama dan penyakit harus dilakukan dengan cepat dan akurat. Tanaman hortikultura tersebut salah satunya adalah bawang merah dan cabai. Sistem pakar dihadirkan sebagai pilihan kedua setelah pakar dalam melakukan konsultasi. Dengan menggunakan metode Expert System Development Life Cycle (ESDLC), penggabungan teknik inferensi forward dan backward chaining untuk diagnosis hama dan penyakit tanaman hortikultura dibuat sebagai solusi atas permasalahan yang ada. Teknik penalaran yang digunakan dalam penelitian ini yakni rule-based reasoning. Hasil penelitian berupa aplikasi yang dapat dijadikan sarana

*) Penulis korespondensi (Ginanjar Wiro Sasmito)

Email: anjar.dosen@gmail.com konsultasi untuk melakukan diagnosis terhadap hama dan penyakit tanaman hortikultura, yakni berupa bawang merah dan cabai. Dengan aplikasi ini petani dapat mengetahui tindakan cepat yang harus dilakukan apabila lahan pertaniannya terserang hama dan penyakit, tanpa menunggu konsultasi dengan seorang pakar untuk melakukan penanganan. Aplikasi yang dihasilkan juga dapat dijadikan sebagai sistem pembelajaran bagi petani tentang hama dan penyakit tanaman hortikultura.

Kata Kunci: Sistem Pakar;Forward chaining;Backward Chaining; Rule-based Reasoning; ESDLC; Tanaman Hortikultura

\section{Pendahuluan}

Hortikultura merupakan komoditas pertanian khas tropis yang potensial untuk dikembangkan di Indonesia dan memiliki prospek yang cerah di masa mendatang sekaligus sebagai sumber perolehan devisa bagi Indonesia. Tanaman hortikultura yang banyak dibudidayakan di Indonesia, namun bila dilihat dari hasilnya masih belum memuaskan. Hal ini disebabkan oleh berbagai faktor, di antaranya adalah teknik budidaya, kondisi lingkungan serta gangguan hama dan penyakit. Hama dan penyakit merupakan kendala utama dalam budidaya tanaman pertanian yang dapat menurunkan produksi hingga $40 \%$ [1].

Keterbatasan yang dimiliki seorang expert terkadang menjadi kendala bagi para petani yang akan melakukan konsultasi guna menyelesaikan suatu permasalahan untuk mendapatkan solusi terbaik. Dalam hal ini sebuah sistem pakar untuk diagnosis hama dan penyakit tanaman hortikultura dibuat guna dijadikan sebagai sarana untuk konsultasi, sarana pembelajaran di sebuah instansi Dinas Pertanian atau Laboratorium Pertanian serta dapat dijadikan sebagai alat bantu (tool) bagi seorang pakar dalam mendiagnosis dan mensosialisasikan jenis hama dan penyakit dua jenis tanaman hortikultura tersebut, yakni bawang merah dan cabai. Dengan aplikasi sistem pakar tersebut pula sebuah Kelompok Tani dapat dengan mudah membantu para petani yang tengah mengalami permasalahan mengenai hama dan penyakit tanaman hortikultura beserta solusi terbaik yang harus ditempuh tanpa bergantung sepenuhnya terhadap seorang pakar serta dapat berbagi informasi atau pengetahuan antar sesama petani berdasarkan atas sistem tersebut. 
Komparasi teknik inferensi forward dan backward chaining di terapkan karena data dan fakta dalam melakukan proses penelitian telah didapatkan, dan dari data atau fakta tersebut dapat dibuat sebuah sistem yang akan memberikan sebuah konklusi atau solusi berdasarkan atas sekumpulan data dan fakta tersebut. Dengan menggunakan teknik inferensi ini pula peluang dalam mendapatkan suatu konklusi yang lebih spesifik dapat dengan mudah didapatkan [2].

Dengan menggunakan metode rule-based reasoning yang memiliki pola if-then pada basis pengetahuan dalam aplikasi diagnosis sistem pakar ini pula, maka pakar dengan kinerjanya dapat menyelesaikan masalah tersebut secara berurutan [3]. Dengan metode pendekatan ini, aturan-aturan yang telah dihasilkan dapat dikaji ulang oleh pakar untuk dapat diperbaiki atau dimodifikasi guna mendapatkan hasil yang lebih baik. Di samping itu, metode ini juga digunakan apabila dibutuhkan penjelasan tentang jejak (langkah-langkah) dalam mendapatkan suatu pencapaian solusi atau langkahlangkah mengenai pencapaian terhadap hasil suatu diagnosis terhadap hama dan penyakit tanaman hortikultura.

Sistem Pakar diterapkan dalam beberapa bidang kehidupan, misalnya dalam diagnosis penyakit padi. Dalam penelitian ini sistem pakar yang dikembangkan pada area pertanian, menjelaskan desain dan pengembangan basis aturan dalam sistem pakar menggunakan shell ESTA (Expert System for Text Animation). Penelitian ini menghasilkan sebuah sistem yang mengintegrasikan basis pengetahuan terstruktur beserta dengan solusi atas permasalahan tersebut. Sistem yang dihasilkan telah diuji antara dataset yang ada dengan pakar bidang penyakit tanaman padi [4].

Sistem pakar digunakan dalam diagnosis penyakit manusia. Dalam penelitian ini, identifikasi pengobatan yang akurat pada manusia bergantung pada metode yang digunakan dalam mendiagnosis penyakit. Sebuah sistem pakar untuk diagnosis (DExS) dapat membantu banyak dalam mengidentifikasi penyakit tersebut dan menjelaskan metode pengobatan yang harus dilakukan. Sistem pakar pada penelitian ini menggunakan aturan penelusuran dan memainkan peran penting dalam memberikan metode tertentu untuk diagnosis pengobatan $[5]$.

Sistem pakar diterapkan untuk diagnosis penyakit mata. Penelitian ini menyajikan desain sistem pakar yang bertujuan untuk menyediakan interface bagi pasien dengan latar belakang gejala penyakit yang beragam dan digunakan untuk diagnosis yang cocok dari beberapa penyakit mata. Terdapat banyak penyakit mata yang dapat dideteksi dari gejala-gejala yang ada. Bahasa CLIPS pada penelitian ini digunakan sebagai alat untuk merancang sistem pakar. Evaluasi awal dari sistem pakar pada penelitian ini dilakukan dan umpan balik positif diterima dari pengguna [6].
Sistem pakar dimanfaatkan untuk pendeteksian dan penanganan dini pada penyakit sapi. Pada penelitian ini sistem pakar diimplementasikan dengan menggunakan aplikasi berbasis mobile. Namun, dengan sumber daya komputasi yang terbatas pada perangkat mobile, diperlukan representasi pengetahuan yang tepat sehingga dapat mengoptimalkan kinerja aplikasi pada perangkat mobile. Berdasarkan atas hasil penelitian, didapatkan bahwa kinerja dari frame-based lebih handal dibandingkan rule-based dari segi tingkat kevalidan dan tingkat kecepatan proses diagnosis [7].

Penelitian serupa yang memanfaatkan sistem pakar adalah dalam mendeteksi tingkat resiko penyakit jantung koroner. Pada penelitian ini sistem pakar menggunakan metode Dempster Shafer. Hasil diagnosis penyakit jantung koroner yang dihasilkan oleh sistem pakar sama dengan hasil perhitungan secara manual dengan menggunakan teori mesin inferensi Dempster Shafer. Sehingga dapat disimpulkan bahwa sistem pakar yang telah dibangun dapat digunakan untuk mendiagnosis penyakit jantung koroner [8].

Dalam dunia kesehatan, sistem pakar dimanfaatkan guna diagnosis penyakit kulit akibat infeksi jamur. Sistem pakar diagnosis penyakit kulit ini merupakan suatu sistem pakar yang dirancang sebagai alat bantu untuk mendiagnosis jenis penyakit kulit pada manusia yang disebabkan oleh infeksi jamur. Sistem pakar ini dibangun untuk memberikan informasi mengenai diagnosis penyakit kulit akibat infeksi jamur pada manusia serta cara penatalaksanaannya, dan dapat menghasilkan suatu alternatif solusi yang cepat dalam menentukan jenis penyakit kulit infeksi jamur dengan melihat gejala yang timbul tanpa harus berkonsultasi dengan seorang pakar. Sistem pakar ini dibangun menggunakan metode backward chaining untuk pengambilan keputusannya [9].

Perbedaan penelitian yang dilakukan oleh peneliti terdahulu dengan penelitian ini salah satunya adalah pada penggunaan teknik inferensi yang digunakan. Dalam penelitian ini dilakukan penggabungan teknik inferensi, yakni forward chaining dan backward chaining sehingga hasil penelitian lebih sempurna dikarenakan penggabungan teknik inferensi akan lebih memudahkan pengguna dalam melakukan diagnosis dengan aplikasi yang dihasilkan. Di samping itu, pengguna juga akan mendapatkan konklusi/kesimpulan yang lebih spesifik, sehingga proses diagnosis terhadap permasalahan hama dan penyakit tanaman hortikultura dapat dilakukan dengan cepat, jelas dan akurat. 


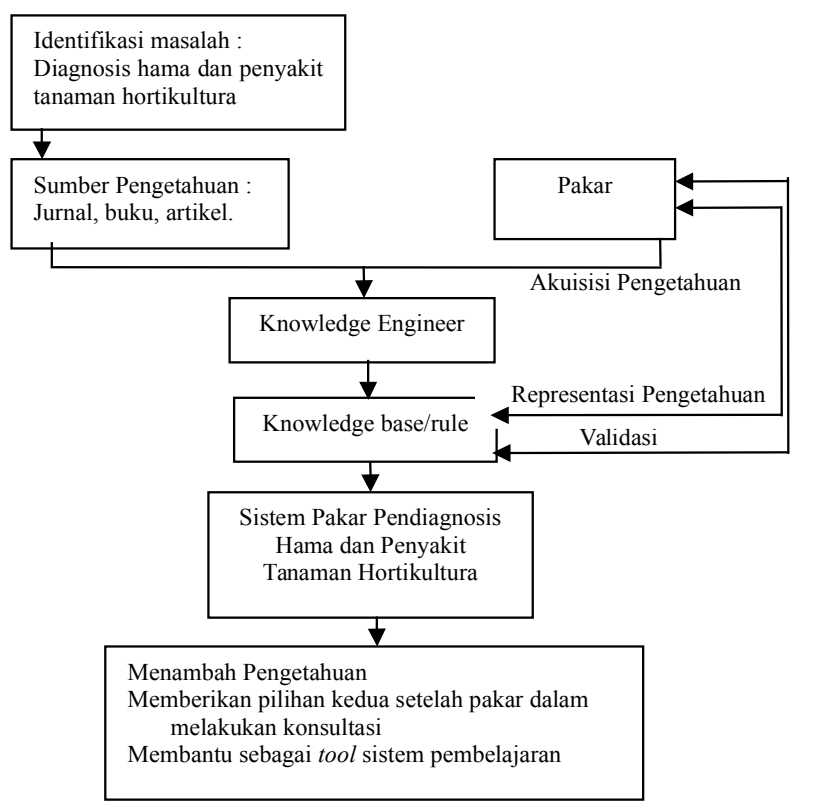

Gambar 1. Kerangka Pemikiran

\section{METODE}

Kerangka pikiran dalam penelitian ini ditunjukkan dalam Gambar 1. Kerangka tersebut menjelaskan alur / tahapan proses dalam penelitian dan hasilnya. Sistem pakar diagnosis hama dan penyakit tanaman hortikultura ini dikembangkan dengan metode Rekayasa Sistem Berbasis Komputer berdasarkan prinsip-prinsip Siklus Pengembangan Sistem Pakar atau ESDLC (Expert System Development Life Cycle). ESDLC terdiri dari perencanaan (planning), akuisisi pengetahuan (knowledge acquisition), implementasi (coding), evaluasi (evaluating) (Gambar 2).

Proses pembuatan aplikasi sistem pakar pendiagnosis hama dan penyakit tanaman hortikultura menggunakan teknik inferensi forward dan backward chaining rule-based reasoning adalah sebagai berikut :

a. Menentukan objek penelitian yang akan diterapkan dalam sistem pakar, yaitu tanaman hortikultura yang terdiri dari bawang merah dan cabai.

b. Mengumpulkan dan mengidentifikasi data-data mengenai jenis hama dan penyakit tanaman tersebut berupa gejala fisik yang menjangkiti tanaman, gambar hama-penyakit atau tanaman yang terserang hama-penyakit, keterangan hama dan penyakit serta pengendalian atau solusi terbaik yang harus ditempuh.

c. Menganalisis permasalahan hama dan penyakit yang ada dengan menelusuri gejala-gejalanya. Selanjutnya dilakukan penelusuran untuk memastikan apakah masalah hama dan penyakit tanaman bawang merah dan cabai bisa diakomodasi oleh sistem pakar dengan memberikan solusi terbaik yang harus ditempuh atau tidak.

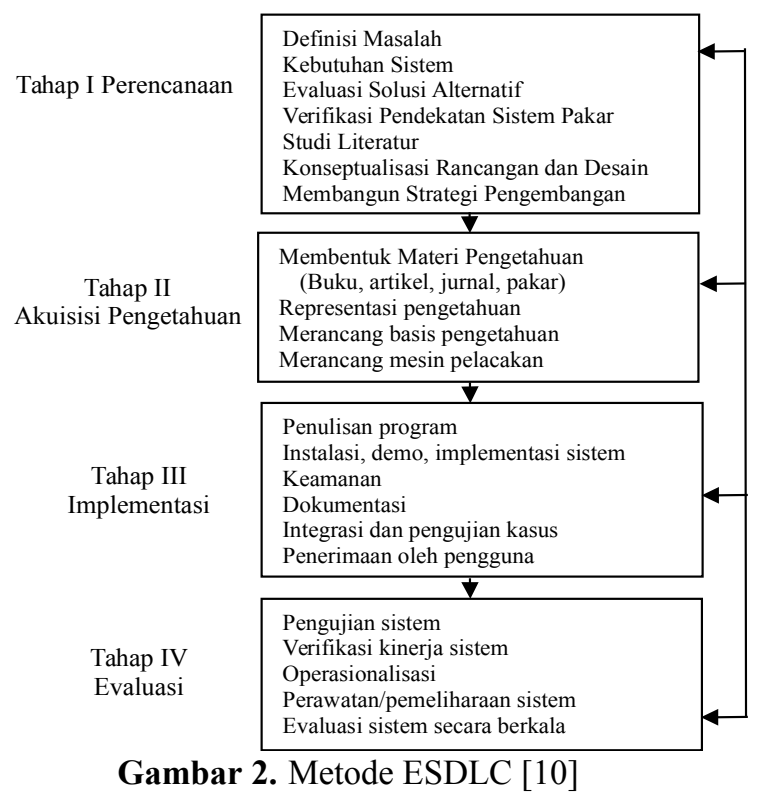

d. Pemilihan pakar yang akan diakuisisi pengetahuannya untuk diwawancarai dan diobservasi pekerjaannya berupa pengalaman praktik dan pemahamannya tentang hama dan penyakit tanaman bawang merah dan cabai.

e. Membuat perancangan masukan dan keluaran. Masukan sistem pakar berupa gejala-gejala yang ditimbulkan oleh hama-penyakit dan jenis hama dan penyakit, sedangkan keluaran berupa jenis hama-penyakit atau gejala-gejala tanaman yang terserang hama dan penyakit, gambar hamapenyakit atau gambar tanaman yang terserang hama-penyakit, keterangan hama-penyakit, serta solusi terbaik yang harus dilakukan untuk menangani tanaman yang terserang hama-penyakit.

f. Arsitektur sistem pakar

Secara teknis arsitektur desain sistem pakar diagnosis hama dan penyakit tanaman hortikultura dibagi menjadi tiga bagian, yaitu antarmuka, aplikasi dan keluaran. Antar muka ini dapat digunakan pengguna dalam berinteraksi dengan aplikasi sistem pakar, bagian ini digunakan untuk mengakses objek informasi yang diperlukan. Bagian aplikasi dari sistem pakar ini berisi pengetahuan dan mesin inferensi. Semua gejalagejala hama dan penyakit beserta aturannya disimpan dalam basis pengetahuan. Untuk menjembatani antara antar muka dan basis pengetahuan, maka mesin inferensi yang menjadi kemudi. Semua masukan yang berupa gejala-gejala penyakit akan dikaitkan dengan jenis hama dan penyakit yang sesuai. Keluaran dari sistem pakar ini adalah jenis hama dan penyakit serta jenis-jenis gejala tanaman yang terserang hama dan penyakit, keterangan hama dan penyakit, gambar hama dan penyakit serta solusi terbaik yang ditempuh. 


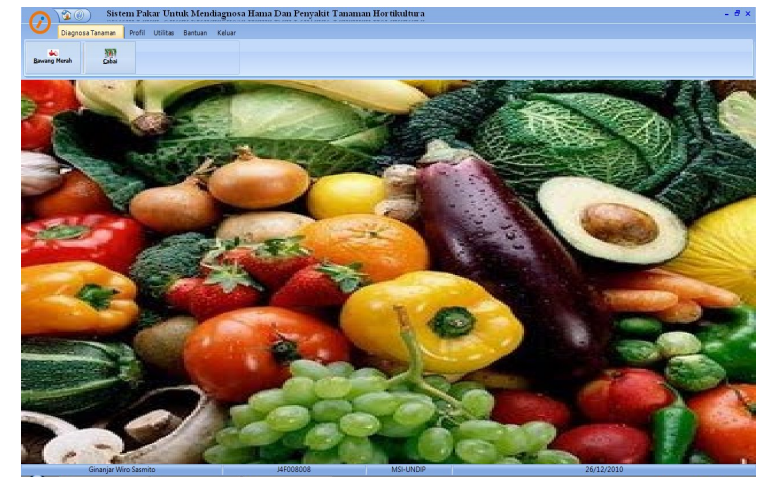

Gambar 3. Мепи Utama Aplikasi

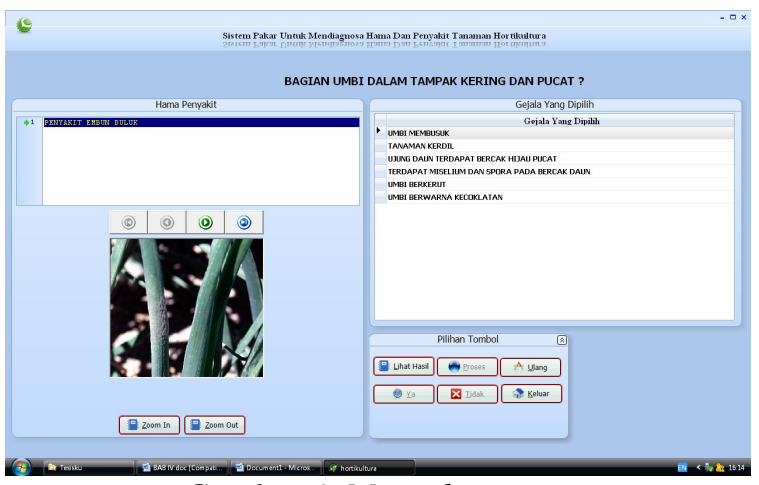

Gambar 4. Menu diagnosis

Antar muka pemakai berfungsi sebagai jembatan atau media komunikasi yang menghubungkan pemakai dengan komputer. Dalam hal ini aplikasi sistem pakar dibuat sebagai antar muka pemakai untuk memberikan kemudahan yang berisi pengetahuan dan dapat ditingkatkan kepakarannya. Perangkat lunak ini menggunakan tampilan visual menu dan sub-sub menu yang user-friendly sehingga dapat memberikan kemudahan dalam konsultasi maupun dalam pengisian basis pengetahuan beserta aturan-aturannya.

\section{Hasil dan Pembahasan}

Rancangan aplikasi yang dihasilkan dari penelitian menggunakan DFD (Data Flow Diagram). DFD merupakan alat yang akan digunakan pada metodologi pengembangan sistem yang terstruktur (structured analisys and design)[11]. Aplikasi ini dibangun dengan menggunakan bahasa pemrograman Borland Delphi dan database Paradox, aplikasi sistem pakar diagnosis hama dan penyakit tanaman hortikultura yang menggunakan teknik inferensi forward dan backward chaining serta dengan metode penelusuran rule-based reasoning ini telah berhasil dibuat (Gambar 3 dan Gambar 4).

Pembuatan program dilakukan sesuai dengan perancangan dan desain yang telah dibuat sebelumnya. Program juga dibuat agar mudah dalam melakukan penyandian terhadap pengetahuan-pengetahuan yang terdapat dalam knowledge base dengan menggunakan pendekatan berbasis aturan (rule base reasoning) serta forward dan backward chaining sebagai teknik inferensinya.

Instalasi program dilakukan pada salah satu tempat praktik (tempat penelitian) disertai dengan melakukan demo di hadapan dua orang pakar yang pengetahuannya telah diakuisisi dan beberapa orang dari salah satu kelompok tani di Kabupaten Brebes, kemudian dilanjutkan dengan penerapan sistem serta pelatihan kepada salah satu pegawai Dinas Pertanian Tanaman Pangan Dan Hortikultura Kabupaten Brebes yang ditunjuk sebagai Administrator.

Keamanan sistem komputer harus memenuhi beberapa aspek agar data dapat terlindungi dari orang yang tidak berhak menggunakan, sehingga mencegah penyisipan dan penghapusan data (manipulasi data dari luar sepengetahuan yang berhak) [12]. Keamanan aplikasi sistem pakar yang telah dihasilkan pada penelitian ini telah memenuhi beberapa aspek tersebut, karena aplikasi telah dilengkapi dengan pengisian user id dan password (yang telah teregistrasi oleh Administrator) sebelum menggunakannya, aplikasi juga akan menghentikan prosesnya jika dalam pengisian user id dan password terjadi kesalahan sampai tiga kali.

Dokumentasi digunakan untuk mengarsip datadata pada aplikasi tersebut agar ketika terjadi kerusakan pada data dan sistem masih ada file cadangan yang tersedia, pendokumentasian dilakukan dengan dokumentasi terhadap sistem, yaitu dengan menyimpan file asli sistem (yang belum terinstall) pada drive lain atau $\mathrm{CD}$, dan dokumentasi terhadap hasil diagnosis, yaitu dengan mencetak hasil diagnosis yang telah dilakukan.

Pengujian integrasi dilakukan dengan mengkontruksi struktur program untuk mengungkap kesalahan sehubungan dengan penggabungan modulmodul secara bersama-sama. Integrasi dilakukan dengan pendekatan top-down terhadap struktur program (Gambar 5). Modul diintegrasikan dengan menggerakkan ke bawah melalui hierarki kontrol yang dimulai dari modul menu utama. Subprogram terhadap menu utama digabungkan ke dalam struktur dengan cara depth-first.

Pada saat aplikasi sistem pakar pendiagnosis hama dan penyakit tanaman hortikultura dijalankan, halaman login muncul. Pemakai yang diberi hak akses untuk login adalah level Administrator dan level User yakni dengan memasukkan Nama Pengguna dan Kata Sandi. Terdapat 3 pengujian kasus, yaitu pengujian setiap menu pada aplikasi, pengujian proses tanya jawab dan pengujian modifikasi terhadap basis pengetahuan.

Pengujian sistem dilakukan dengan melakukan pengujian black-box terhadap semua fungsi dalam aplikasi. Hasil pengujian sistem menggunakan black box dapat dinyatakan bahwa semua masukan yang terdapat pada aplikasi sistem pakar yang dihasilkan, akan memunculkan pesan kesalahan apabila User atau Admin melakukan kesalahan dalam memasukkan data. 


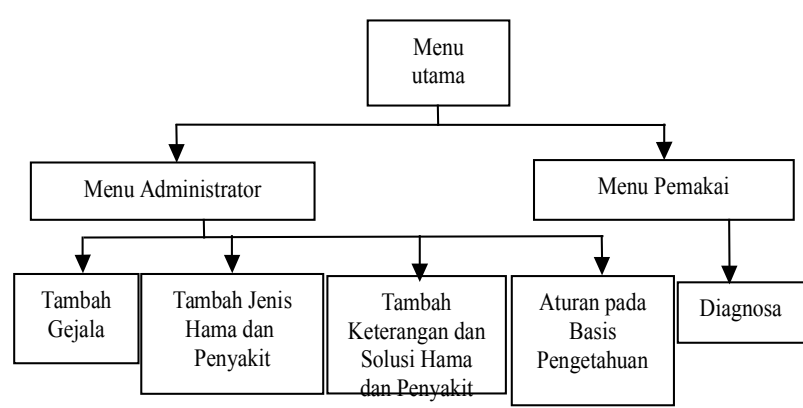

Gambar 5. Bagan Integrasi Sistem

Verifikasi kinerja sistem telah dilakukan dengan melakukan pengujian terhadap hasil diagnosis, yakni dengan cara membandingkan hasil diagnosis pakar dengan aplikasi sistem pakar. Dari hasil perbandingan tersebut dapat disimpulkan bahwa diagnosis menggunakan aplikasi sistem pakar dan diagnosis yang dilakukan pakar memiliki hasil berupa kesimpulan dan solusi yang sama.

Tujuan evaluasi sistem adalah untuk mengetahui sejauh mana hasil dari aplikasi sistem pakar bermanfaat dan untuk menjamin bahwa sistem baru dapat memberikan hasil sesuai dengan yang diharapkan. Untuk itu, dilakukan tes menggunakan kuesioner yang terdiri dari 10 responden yaitu 2 orang pakar, 6 orang petani dari Kelompok Tani Bahagia I Kabupaten Brebes dan 2 masyarakat umum.

Operasionalisasi dilakukan di salah satu tempat penelitian yaitu di Dinas Pertanian Tanaman Pangan dan Hortikultura Kabupaten Brebes dan selanjutnya dilakukan di Laboratorium Pengamatan Hama dan Penyakit Pemalang serta di berbagai tempat kelompok tani dengan cara menerapkan aplikasi sistem pakar tersebut pada perangkat keras komputer. Sedangkan pemeliharaan sistem dilakukan dengan pemeriksaan periodik terhadap data (knowledge) pada aplikasi tersebut, namun dikarenakan keterbatasan waktu maka penelitian tidak sampai pada pemeliharaan sistem.

Aplikasi sistem pakar telah berhasil untuk mendiagnosis hama dan penyakit tanaman bawang merah dan cabai seperti halnya diagnosis di tanaman padi [4] dan deteksi beragam penyakit lain di [5-9]. Aplikasi ini menggunakan rule-based reasoning [3], walaupun tidak lebih handal daripada frame-based dari sisi validitas dan kecepatan proses [7]. Aplikasi ini menggunakan 2 teknik inferensi yang dapat dipilih oleh pengguna, yaitu forward chaining [6] dan backward chaining [9], sehingga memudahkan pengguna dalam melakukan diagnosis berdasarkan karakteristik hama dan penyakit.

\section{KESIMPULAN}

Aplikasi sistem pakar telah dikembangkan dan diterapkan pada area pertanian, yakni untuk mendiagnosis hama dan penyakit tanaman hortikultura, meliputi bawang merah dan cabai dengan menggunakan teknik inferensi forward dan backward chaining serta rule base reasoning sebagai teknik pendekatan/penelusurannya pada basis pengetahuan (knowledge base). Aplikasi ini mempermudah pengguna dalam menggunakan aplikasi karena memiliki 2 pilihan dalam melakukan proses diagnosis dengan penggabungan teknik inferensi tersebut, sehingga pengguna juga mendapatkan hasil diagnosis yang lebih spesifik.

\section{UCAPAN TERIMA KASIH}

Terima kasih disampaikan kepada Kepala laboratorium Pengamatan Hama dan Penyakit Pemalang dan Kepala Dinas Pertanian, Tanaman Pangan dan Hortikultura Kabupaten Brebes atas data yang telah diberikan selama penelitian.

\section{DAfTar Pustaka}

[1] Badan Penelitian dan Pengembangan Pertanian, "Kebijakan Tanggap Ledakan Hama Penting Tanaman Perkebunan", Kementrian Pertanian, 2011

[2] G. R. Baur, and D. V. Pigford, "Expert System For Business : Concept and Implementations", Boyd \& Fraser Publishing Company, Boston-USA, 1990

[3] J. P. Ignizio, "Introduction To Expert Systems : The Development and Implementation of Rule Based Expert System", McGraw-Hill International Editions, 1991

[4] S. K. Sharma, K. R. Singh, and A. Singh, "An Expert System for diagnosis of diseases in Rice Plant", International Journal of Artificial Intelligence, vol.1, no. 1,2010

[5] P. S. K. Patra, "An Expert System for Diagnosis Of Human Diseases", International Journal of Computer Applications, vol. 1, no. 13, 2010

[6] S. S. Naser, and A. Z. A. Ola, "An Expert System For Diagnosing Eye Diseases Using Clips", Journal of Theoretical and Applied Information Technology, vol. 4, no. 10, 2008

[7] W. Ardianto, W, Anggraeni, and A. Mukhlason, "Pembuatan Sistem Pakar Untuk Pendeteksian dan Penanganan Dini Pada Penyakit Sapi Berbasis Mobile Android dengan kajian Kinerja Teknik Knowledge Representation", Jurnal Teknik ITS, vol. 1, no. 1,2012

[8] E. G. Wahyuni, and W. Prijodiprojo, "Prototype Sistem Pakar untuk Mendeteksi Tingkat Resiko Penyakit Jantung Koroner dengan Metode DempsterShafer", IJCCS-Indonesian Journal of Computing and Cybernetics Systems, vol.7, no.2, 2013, pp. 133144

[9] D. Agustina, H. Mustafidah, and M. R. Purbowati, "Sistem Pakar Diagnosa Penyakit Kulit Akibat Infeksi Jamur", JUITA (Jurnal Informatika), vol. 4 Nomor 2, 2016 
[10] E. Turban, "Expert System and applied Artificial Intelligence", Macmilan Publishing Company, New York, 1995
[11] G. W. Sasmito, "Sistem Informasi : Konsep Dasar, Analisis dan Perancangan", Harin Sentosa, 2015

[12] D. Ariyus, "Computer Security", Edisi 1. Yogyakarta: Andi, 2006. 